УДК 34.01

DOI 10.52575/2712-746X-2021-46-2-361-367

\title{
Органика общей и правовой глобализации
}

\author{
Макогон Б.В, Беляева Г.С., Мирошников Е.В. \\ Белгородский государственный национальный исследовательский университет, \\ Россия, 308015, г. Белгород, ул. Победы, 85 \\ E-mail: makogon@bsu.edu.ru,belyaeva_g@bsu.edu.ru,miroshnikov@bsu.edu.ru
}

\begin{abstract}
Аннотация. Представлена авторская позиция по проблематике современных представлений о качествах процесса глобализации и соответствующей правовой ипостаси. Принимая во внимание как общие характеристики глобализации, так и те, которые обусловлены современным ее периодом и правовым измерением, авторами рассмотрена сущность глобализации с учетом теории пределов, конфликтологии; определена органика взаимодействия в закольцованной глобализационноправовой системе, а также диалектики глобализации, выражающейся в единстве и борьбе противоположных тенденций и сил. Сделаны выводы о положительных и отрицательных следствиях глобализационных процессов, а также о роли фундаментальных юридических знаний и представлений в охране и защите интересов современной государственности. В заключение авторами оформлено представление об угрозах телеологической коррупции при формировании концептуальных начал государственно-правового развития современного государства в условиях глобализации и сопутствующих процессов, требующих аналитико-синтезной оценки.
\end{abstract}

Ключевые слова: глобализация, правовая глобализация, процесс правовой глобализации, интеграция.

Для цитирования: Макогон Б.В., Беляева Г.С., Мирошников Е.В. 2021. Органика общей и правовой глобализации. NOMOTHETIKA: Философия. Социология. Право. 46 (2): 361-367. DOI $10.52575 / 2712-746 \mathrm{X}-2021-46-2-361-367$

\section{Organics of general and law globalization}

\author{
Boris V. Makogon, Galina S. Belyaeva, Evgeny V. Miroshnikov \\ Belgorod National Research University, \\ 85 Pobedy St, Belgorod, 308015, Russian Federation \\ E-mail: makogon@bsu.edu.ru, belyaeva_g@bsu.edu.ru,miroshnikov@bsu.edu.ru
}

\begin{abstract}
This article presents the author's position on the problems of modern ideas about the qualities of the globalization process and the corresponding legal hypostasis. With respect to both general globalization characteristics and those that were occasioned by its modern period and legal dimension. The authors consider the essence of globalization, taking into account the theory of limits and conflictology. They also determine the organics of interaction in the looped globalization-legal system. Moreover, the authors designate the dialectics of globalization, expressed in the unity and struggle of opposing tendencies and forces. The conclusions about the positive and negative consequences of globalization processes are drawn in this article, as well as the role of fundamental legal knowledge and ideas in the safety and protection of the modern statehood interests. In conclusion, the authors formulated an idea of the threats of teleological corruption in the formation of conceptual principles of state and legal development of a modern state in the context of globalization and related processes that require analytical and synthesis assessment.
\end{abstract}


Keywords: globalization, law globalization, process of law globalization, integration.

For citation: Makogon B.V., Belyaeva G.S., Miroshnikov E.V. 2021. Organics of general and law globalization. NOMOTHETIKA: Philosophy. Sociology. Law series. 46 (4): 361-367 (in Russian). DOI 10.52575/2712-746X-2021-46-2-361-367

\section{Введение}

Смело заметим, что глобализация определила предыдущее столетие. Две мировые войны, формирование новых финансово-экономических стандартов, вначале попытки, затем действительно создание жизнеспособной международно-правовой системы, которую можно назвать конститутивной, мировое соперничество, на фоне развития технологий перешедшее в гибридное русло, - все это явилось катализаторами, и драйверами, и следствиями/сателлитами глобализации. Сформировавшиеся и продолжающие развиваться нормативные комплексы, претендующие на звание источника суверенитета, государственности, их институтов, человечности, словно обнаружив в современности новый импульс, как волны лавин обрушиваются на государства, их объединения, целые сферы отношений и установки, требуя подчинения и вызывая как таковое, так и обратные реакции.

При этом в каждом периоде уместно говорить о невиданных по своим масштабам трансформациях, что еще раз подтверждает наше отношение к глобализации как к процессу, включающему в себя систему процессов, интенсивность и степень агрессии которого коррелирует с движением цивилизации по пути эволюции, революций и точек бифуркации. Последние, став одним из символов века, закончившего тысячелетие (существует даже отношение к предыдущему столетию как к веку бифуркаций), в нынешнем столетии уже приобрели более массовый, акселерационный характер.

\section{Глобальная интеграция: стремление, конфликт, круговорот}

Отношения представляются всегда реактивными, вопрос лишь в силе реакций, не в последнюю очередь определяющейся силой, объемом, системностью и продолжительностью воздействия.

Глобальные системы информационного обмена и теперь уже полноценного созидания продолжают трансформировать мир с перманентно усиливающимся ускорением; представляются одновременно и средой, и средствами, и инструментами, а зачастую даже аксиологическими ориентирами развития. Четвертая технологическая революция, о которой слишком многие всерьез стали говорить уже на завершающем этапе периода первоначального накопления соответствующего капитала, принесла не только блага, поддержку и возможности, но и ресурсы, соблазны для продвижения политики безоговорочного лидерства и даже диктата в глобализирующемся мире.

Государства в стремлении воплотить в жизнь не только свой потенциал, но и амбиции, тяготеют к сближению финансово-экономических, общесоциальных, культурных, правовых систем; как материальные, так и идеальные, институциональные международные площадки становятся полями утверждения политической воли, демонстрации силы, обозначения мест и ролей в глобальном пространстве не только настоящем и перспективном, но, как это ни парадоксально, и в прошлом.

Суть глобализации - в стремлении к интеграции, на фоне которого процессы конвергенции органически встречаются с глобальной дивергенцией. Такая реактивность, уже упомянутая выше, видится логичной и согласующейся с концептуальными положениями теории систем.

Существует мнение, в соответствии с которым глобализация предполагает «глобализирование» одних субъектов другими в целях установления неких общностей для первых 
[Бауман, 2004]. Такой подход представляется довольно интересным в виду того, что в целом иллюстрирует расслоение мирового сообщества и дальнейшее укрепление такового, даже, возможно, формальное закрепление, что является одним из наиболее актуальных следствий и в то же время двигателем глобализации. При этом представленная позиция может быть уязвимой и одновременно справедливой.

Поясним, что, по нашему мнению, в таких рамках глобализация трактуется чрезмерно узко; тот факт, что субъекты, обладающие такими возможностями, стремятся теми или иными способами и средствами навязать свои правила игры другим, видится именно одним из проявлений глобализации как процесса, основанного на конфликте, ориентированного, в том числе, на указанное. И, конечно же, мы не можем вести речь об установлении в рамках глобализации общностей в прямом их понимании, то есть полностью одного и того же для всех глобализируемых, ведь тогда будет явная коррупция современной гибридной методологии расширения зон влияния, что не отразит реалии сегодняшней ступени развития человечества.

Глобализация - это процесс [Макогон, 2017], который не является конечным, поскольку в случае достижения уровня глобальности в сто процентов, абсолютной унификации социальных связей и их регулирования всеми типами норм, устремлений, мотивационных составляющих, доктрин, сфер существования материальных и идеальных объектов, систем их взаимодействия и саморегулирования произойдет утрата конфликта как элемента, обеспечивающего стабильность и жизнеспособность системы, на котором, по нашему мнению, основаны глобализационные процессы.

Конечно, человеческое общество стремится к интеграции, унификации и гармонизации нормативных систем для упрощения своей эволюции, обмена, совершенствования. Однако, по указанным выше причинам, абсолюта достичь не может. Он представляется объектом, являющимся пределом последовательности событий и действий, которые соответствуют отношениям, складывающимся в процессе глобализации. Соответственно, считаем методологически оправданным вести речь не о некоторой теоретической высшей его точке в будущем, а о наивысшем его плато. На такое плато глобализация может выйти через субъективные и объективные пути, идущие рука об руку.

Субъективный путь определен стремлением субъектов к доминированию на мировой арене. Он комплексный, включает в себя экономическую, политическую, военную, культурную, возможно, в некотором смысле, религиозную телеологию, и в нем усматриваются не только очевидные негативные стороны, но и позитивные аспекты, связанные с управлением глобализацией для нивелирования ее отрицательных сателлитов, таких как безработица, бедность, болезни, экологические проблемы и сопряженные с ними государственные и «правозащитные риски» [Новикова, Анисимов, 2008], смешанность «правозащитных приоритетов» [Мархгейм, Новикова, 2008], «горячие» войны и другое.

Путь объективный - суть естественный процесс сближения и диффузии, провоцируемый комплексом факторов культурной и экономической природы, обусловленный установками на совершенствование среды жизнедеятельности. Он представляется долгосрочным, его интенсивность различается в зависимости от исторических периодов, неравномерна и не зависит от оперативных действий каких-либо субъектов для решения текущих задач и целеполагания как деятельности.

Распространена позиция о преимущественно негативной оценке глобализации. Действительно, современные информационные системы дали возможности для формирования масштабного и крепкого культа западничества, поглощения исконно национальных культур, агрессивной трансформации языков, однополярной санкционной риторики для управления целыми сферами отношений и самоутверждения внеконкурентного лидерства. Глобализация порождает глобальные проблемы, решение которых в принципе не представляется возможным без усложнения международных отношений и соответствующей методологии. 
То есть глобализацию сопровождают свойственные ей сложности, преодолению которых нужна глобализация. Именно поэтому выше мы указали, что рассмотренные объективный и субъективный пути идут рука об руку. Международный терроризм, существование экологических оазисов за счет менее благополучных территорий, трансформация парадигм правопонимания и правового сознания именно на глобальном уровне, тенденция к трактовке, в том числе в межгосударственных и сопряженных отношениях, правоприменения как юридического процесса усмотрения, пересмотр признаков социального государства в угоду глобализации и тотальной цифровизации, сдвиги в функционировании национальных систем конституционного контроля, расширение пространства и свободы использования института правовых ограничений [Макогон, 2013б], киберугрозы при усиливающейся зависимости человечества от непрерывной работы технологий - все это мы уверенно относим к негативным следствиям глобализации, при этом уточняя, что не считаем их непреодолимыми при конструктивном межгосударственном диалоге на международных площадках, система которых, конечно, нуждается в обновлении. Последнее - считаем критичным.

\section{Правовая ипостась глобализации}

Особое значение в условиях глобализирующегося мира приобретает право, на которое возлагаются критичные системные задачи, с одной стороны, по легально-формальному закреплению соответствующих глобализационных тенденций, обеспечению вхождения современных государств в мировое сообщество; с другой - задачи по управлению глобализационными процессами применительно к конкретному государству, по их сдерживанию и направлению в определенное русло, дабы не допустить негативных последствий, связанных в целом с аккультурацией [Иванец, Червонюк, 2003; Рубанов, 1994], с нестыковкой национальных культур и возможностей с воспринимаемыми мировыми веяниями, а также с опасностью попадания в невозвратную, без мощных шоков, зависимость от наиболее, в популярном понимании, развитых стран, заняв место своеобразного придатка в мировом сообществе.

Правовая ипостась глобализации многогранна и отражает все рассмотренные выше характеристики. По аналогии с объективным и субъективным путями определим, что она может рассматриваться как процесс воздействия глобализации на международное и национальное право, а также в обратном порядке. В последнем контексте нами трактуются, к примеру, изменения в законодательстве и доктринах, ограничивающие юрисдикцию международных судебных органов; весь механизм правовой гармонизации, отличный от унификации.

Таким образом, через юридическую процессуальную форму [Макогон, 2013а], включающую стадии производства, режим, процессы глобализации транспонируются в государственно-правовую действительность с выраженно ограничительными [Беляева, 2011] свойствами [Беляева, 2013].

Соответственно, возрастание именно значения глобальных правовых тенденций для национального и международного права коррелирует с глобализацией самого права [Макогон, 2007]; правовые системы по целому ряду параметров сближаются, ведется дискуссия о формировании «глобальной правовой системы» [Боголюбов С. А. и др., 2004]. Право, по нашему представлению, являющееся той формой, которая способна упорядочить отношения, складывающиеся в любых сферах - от экономической и военно-политической экспансии до определения принципов сотрудничества в формировании мироустройства, видится аккумулятором знаний о глобализации и источником власти по управлению ее процессами.

Конечно, в современном витке глобализации можно отметить тенденцию к возрастанию дивергенционных процессов в праве. Однако полагаем, что такие процессы, протекающие с большей или меньшей интенсивностью, можно наблюдать в различные истори- 
ческие периоды. Глобальную правовую дивергенцию мы связываем с устойчивой жизнеспособностью института государственного суверенитета, обеспечивающего уникальность государственности любой страны. К тому же суверенитет можно интерпретировать как ключевую идейно-идеологическую составляющую организации жизни общества и стабильного функционирования единой системы публичной власти. И здесь усматривается важное ограничение в отношении глобализации, суть которого кроется в понимании того, что тон международному праву задается наиболее экономически сильными державами и преимущественно в собственных интересах. Важно, что это далеко не всегда негативно. Но правовая система сдерживания реализации намерений абсолютизации международного права необходимый элемент правовой политики и правовой жизни в интенсивно глобализирующемся мире.

\section{Заключение}

Глобализация органически противоречива. Поддерживая экономический рост, распространение демократии, обмен технологическим опытом, расширяя международное сотрудничество, она влечет риски для устойчивости государственного суверенитета, поглощение национальных культур при одностороннем распространении культурных ценностей, углубление неравенства, зависимости не всегда взаимной, автоматическое проецирование кризисов, возникающих в отдельно взятой стране, на весь мир, угрозу искусственного установления пределов развития государств.

По мере усложнения национальной и глобальной систем к политическим и правовым решениям государств предъявляются все более развернутые требования, которые не представляется возможным в необходимой и достаточной степени удовлетворить без активного участия науки и адекватного научного обобщения.

Учитывая, что в актуальных реалиях процесс глобализации в значительной мере протекает под стараниями управления им, определения его ориентиров и содержания, думается, именно фундаментальная юридическая наука обладает ресурсом для исключения коррупции телеологических предпочтений, нивелирования рассмотренных негативных следствий, эффективного соотнесения возможностей и планируемых государственно-правовых трансформаций.

Кроме того, уместными представляются обоснованные программы развития государств в рамках глобализации. Прогрессивная эволюция государственности, формы сотрудничества с другими странами, совершенствование законодательства и его применения, повышение авторитета закона и ликвидация деформаций правосознания - все это входит в область научной деятельности.

В глобализирующемся мире превалирует не идеологизация уже принятых решений, а уважение к теории, философии, понимание их возрастающей роли в обществе; не нарекания, а стимулирование творческой активности ученых, формулирование широкого и перспективного социального заказа, привлечение науки к разработке и гуманитарной экспертизе важнейших правовых, экономических и социально-политических проектов, - вот принципы отношения практики (политики) к теории (науке).

В рамках заявленной проблематики считаем контрпродуктивным тотальную приоретизацию узкоспециализированных направлений исследований и следование исключительно им в процессе принятия таргетирующих, программных, прогностических и управленческих решений. Для корректности целеполагания «тоннельный» подход в разрешении государственно и общественно значимых дел в условиях глобализации не может быть оправдан необходимостью решения оперативных задач.

Действительно, возможно, иногда велик соблазн действовать рывками. Но рывки по определению темпорально и результативно ограничены, могут вызывать агонию и истощение. При этом рывки телеологии представляются несущими куда большую угрозу, ведь именно они обладают всем потенциалом, чтобы превратить кризис в идеологию, которая 
прочно и надолго может укрепиться уже в государственно-правовой, социальной, национальной традиции.

\section{Список литературы}

1. Бауман 3. 2004. Глобализация. Последствия для человека и общества. М., 188 с.

2. Беляева Г.С. 2011. Необходимость и формы ограничения государственной власти: постановка проблемы. Научные ведомости БелГУ. Сер. Философия. Социология. Право, 14 (109): $114-118$.

3. Беляева Г.С. 2013. К вопросу о понятии правового режима ограничения. Проблемы экономики и юридической практики, 4: 10-12.

4. Боголюбов С. А. и др. Глобализация и развитие законодательства. Очерки. 2004. Отв. ред. Ю.А. Тихомиров, А.С. Пиголкин. М., 464 с.

5. Иванец Г.И., Червонюк В.И. 2003. Глобализация, государство, право. Государство и право, 8: 87-94.

6. Макогон Б.В. 2017. Методологически опорная трактовка юридического процесса. Наука и образование: хозяйство и экономика; предпринимательство; право и управление, 1 (80): 32-35.

7. Макогон Б.В. 2013а. Научная конструкция юридической процессуальной формы и ее виды. Вестник Санкт-Петербургского университета МВД России, 4 (60): 17-22.

8. Макогон Б.В. 2007. Общая характеристика процессов глобализации в правовой сфере. История государства и права, 3: 2-4.

9. Макогон Б.В. 2013б. Понятие и процессуальные виды правовых ограничений. Наука и образование: хозяйство и экономика; предпринимательство; право и управление, 8 (39): 40-46.

10. Мархгейм М.В., Новикова А.Е. 2008. Правозащитные приоритеты в воззрениях отечественных представителей либеральной и консервативной научных школ. История государства и права, 6: 38-40.

11. Новикова А.Е., Анисимов А.П. 2008. Экологические правозащитные риски: проблемы теории и практики. Адвокатская практика, 4: 5-7.

12. Рубанов А.А. 1994. Теоретические основы международного взаимодействия национальных правовых систем. М., 287 с.

\section{References}

1. Bauman Z. 2004. Globalizatsiya. Posledstviya dlya cheloveka I obschestva [Globalization. Consequences for the individual and society]. M., $188 \mathrm{p}$.

2. Belyaeva G.S. 2011. Neobkhodimost' I formy ogranicheniya gosudarstvennoy vlasti: postanovka problem [Necessity and forms of restriction of state power: problem statement]. Nauchnye vedomosti BelGU. Ser. Filosofia. Sotsiologiya. Pravo, 14 (109): 114-118.

3. Belyaeva G.S. 2013. K voprosu o ponyatii pravovogo rezhyma ogranicheniya [On the concept of the restriction legal regime]. Problemy ekonomiki i yuridicheskoj prartiki, 4: 10-12.

4. Bogolyubov S. A. et al. Globalizatsiya i razvitie zakonodatelstva. Ocherki [Globalization and the development of legislation. Essays]. 2004. Ed. YU.A. Tikhomirov, A.S. Pigolkin. M., 464 p.

5. Ivanec G.I., Chervonjuk V.I. 2003. Globalizacija, gosudarstvo, pravo [Globalization, state, law]. Gosudarstvo i pravo, 8: 87-94.

6. Makogon B.V. 2017. Metodologicheski opornaja traktovka juridicheskogo processa [Methodologically supporting interpretation of the legal process]. Nauka i obrazovanie: hozjajstvo i jekonomika; predprinimatel'stvo; pravo i upravlenie, 1 (80): 32-35.

7. Makogon B.V. 2013. Nauchnaya konstruktsiya yuridicheskoj protsessual'noj formy i ee vidy [Scientific construction of the legal procedural form and its types]. Vestnik Sankt-Peterburgskogo universiteta MVD Rossii, 4 (60): 17-22.

8. Makogon B.V. 2007. Obshhaja harakteristika processov globalizacii v pravovoj sfere [General characteristics of the processes of globalization in the legal sphere]. Istorija gosudarstva i prava, 3:2-4.

9. Makogon B.V. (2). 2013. Ponjatie i processual'nye vidy pravovyh ogranichenij [Concept and procedural types of legal restrictions]. Nauka i obrazovanie: hozjajstvo i jekonomika; predprinimatel'stvo; pravo i upravlenie, 8 (39): 40-46.

10. Markhgeym, M.V., Novikova A.E. 2008. Pravozashhitnye prioritety v vozzrenijah otechestvennyh predstavitelej liberal'noj i konservativnoj nauchnyh shkol [Human rights priorities in the 
views of domestic representatives of the liberal and conservative scientific schools]. Istorija gosudarstva $\mathrm{i}$ prava, 6: $38-40$.

11. Novikova A.E., Anisimov A.P. 2008. Ekologicheskie pravozashchitnye riski: problemy teorii I praktiki [Environmentalhuman rights risks: problems of theory and practice]. Advokatskaya praktika, 4: $5-7$.

12. Rubanov A.A. 1994. Teoreticheskie osnovy mezhdunarodnogo vzaimodejstvija nacional'nyh pravovyh sistem [Theoretical foundations of international interaction of national legal systems]. M., $287 \mathrm{p}$.

\section{ИНФОРМАЦИЯ ОБ АВТОРАХ}

Макогон Борис Валерьевич, доктор юридических наук, доцент, профессор кафедры административного права и процесса юридического института Белгородского государственного национального исследовательского университета, г. Белгород, Россия

Беляева Галина Серафимовна, доктор юридических наук, профессор, заведующая кафедрой административного права и процесса юридического института Белгородского государственного национального исследовательского университета, г. Белгород, Россия

Мирошников Евгений Васильевич, кандидат экономических наук, доцент кафедры административного права и процесса юридического института Белгородского государственного национального исследовательского университета, г. Белгород, Россия

\section{INFORMATION ABOUT THE AUTHORS}

Boris V. Makogon, doctor of law, associate professor, professor of the Department of Administrative Law and Procedure of the Law Institute, Belgorod State National Research University, Belgorod, Russia

Galina S. Belyaeva, doctor of law, professor, Head of the Department of Administrative Law and Procedure of the Law Institute, Belgorod State National Research University, Belgorod, Russia

Evgeny V. Miroshnikov, candidate of economics, associate professor of the Department of Administrative Law and Procedure of the Law Institute, Belgorod State National Research University, Belgorod, Russia 